\title{
Revisiting STREMII: Social Media Crisis Communication During Hurricane Matthew
}

\author{
Margaret C. Stewart (10) and Cory Young ${ }^{b}$ \\ aDepartment of Communication, University of North Florida, Jacksonville, \\ Florida, USA; 'bepartment of Strategic Communication, Ithaca College, Ithaca, \\ New York, USA
}

\begin{abstract}
Social media platforms influence the flow of information and technologically mediated communication during a storm. In 2015, Stewart and Wilson introduced the STREMII (pronounced STREAM-ee) as a six-phase model for social media crisis communication in an effort to assist institutions and organizations during unanticipated events, using the crisis of Hurricane Sandy as an applied example. Since the inception of the model, several advancements in social media strategy have revealed the opportunity for further development. This current work presents a revision of the original model, emphasizing the need for ongoing social listening and engagement with target audiences. These aspects of the revised model are discussed in interpersonal and organizational contexts related to examples of social media use during the October 2016 Atlantic Hurricane Matthew.
\end{abstract}

KEYWORDS: Social media; crisis management; situational crisis communication theory; STREMII model; Hurricane Matthew

The events of Hurricane Matthew in October 2016 resulted in a devastating crisis which was fully depicted via social media to engaged audiences. This hurricane event occurred during a time of innovative developments among several social media outlets, including Facebook Live, safe check-ins, and SnapChat stories. In 2015, Stewart and Wilson introduced the STREMII (pronounced STREAM-ee), a six-phase model for social media crisis communication, in an effort to aid organizations, agencies, and institutions during unanticipated events, using the crisis of Hurricane Sandy as an applied example.

CONTACT Margaret C. Stewart, PhD • E-mail: m.c.stewart@unf.edu • Department of Communication, University of North Florida, Building 14D-Office \#2021, Jacksonville, FL 32224, USA 
Since the inception of the model just 2 short years ago, two relevant phenomena occurred. First, several advancements in social media strategy have revealed the opportunity for further development of the original STREMII model. Recognizing the increasing use of social media platforms and the ways in which they influence the flow of information and communication during a storm, it is critical to understand the benefits and pitfalls to social media communication during crisis events. Second, the recent increase in hurricane crises has also contributed to the relevancy of revisiting the original work on the STREMII model at this time. This article presents a revised development of the model, emphasizing the needs for ongoing social listening and engagement with target audiences throughout the crisis event at all of its phases. These aspects of the revised model are discussed in interpersonal and organizational contexts related to the examples of social media use during Hurricane Matthew. Through this discussion, the need for further practical development and empirical testing is recognized and explored.

\section{Review of Literature}

Noting the limited research in crisis communication and social media literature, particularly involving hurricane events, Stewart and Wilson (2015) introduced the STREMII (pronounced STREAM-ee) model to "take into consideration the need for organizations to monitor and respond to contemporary communication processes and to develop a social media strategy and/or crisis management plan for when a crisis arises" (p. 639). The model is theoretically grounded in Coombs's (2007) situational crisis communication theory and the life cycle phases of a crisis-before, during, and after the event. Using Hurricane Sandy as an example, Stewart and Wilson (2015) captured this cyclical process of six interconnected elements: (a) social listening, (b) targeting audience(s), (c) engaging and responding, (d) monitoring and evaluating, (e) interacting, and (f) implementing changes. As the intensity, strength, and numbers of hurricanes increase, so too does the reliance on social media by organizations and individuals. Since the inception of the model, several advancements to social media platforms and updates to best practices for crisis communication have revealed further developments 
of the model. The new developments to STREMII resulting from these advancements are discussed using examples from the more recent events of Hurricane Matthew. In the section that follows, an overview of the timeline and events of Hurricane Matthew within the state of Florida is provided. Additionally, we summarize the state of social media at the time that the storm occurred in October 2016.

\section{Timeline of Hurricane Matthew Events}

Hurricane Matthew was the 13th tropical storm of the 2016 hurricane season. Hurricane Matthew has been recognized as an especially devastating storm, according to Drye (2016). The storm is estimated to have imposed roughly $\$ 10$ billion in damage in the United States along the Atlantic coast from Florida to North Carolina. The storm evolved from Tropical Storm Matthew into a hurricane on the afternoon of September 29, 2016. It started out as a minimal hurricane, yet by the time the storm made landfall in Haiti and Cuba on October 4, 2017, it was a Category 4 (Drye, 2016).

By October 6, 2017, the storm had reached the United States. Although the hurricane's eye wall never touched land in Florida as it continued its way north, the storm remained a powerful Category 2 hurricane as it swept up the Atlantic coast of the southeastern part of the United States. By October 8, 2017, as the storm made it to coastal Georgia and South Carolina, the associated flooding from the storm was devastating many areas. The conditions were so serious in Orlando, Florida, that Walt Disney World closed-only the fourth time since the park's opening in 1971 (Drye, 2016).

While the physical storm surged through the American coastal Southeast, social media experienced their own storm of activity. When considering social media during hurricane events, it is critical to recognize the powerful role and influence that social media platforms have in the flow of information during the storm. To appreciate the need for ongoing development of the STREMII model in the dynamic social media climate, it is necessary first to consider the historical role of social media during Hurricane Matthew and then to compare the data on social media use during Hurricane Sandy in 2012 to Hurricane Matthew in 2016. 
Hurricane Matthew: "The First Truly Social Media Hurricane" A writer for the Palm Beach Post acknowledged this phenomenon, exclaiming that Hurricane Matthew "broke the ground for being the area's first truly social-media hurricane... as the tech savvy took to live streaming, Facebook, Twitter, Instagram and SnapChat to chronicle the event" (Pacenti, 2016). During Hurricane Matthew, social media features including Facebook Live, safe check-ins, and specified SnapChat stories captured and broadcast the storm events online to a national and global audience. A WTHR Indianapolis station staff member (WTHR Indianapolis, 2016) netted various tweets, videos, and memes during Hurricane Matthew as "the story [was] unfolding in real time on social media as residents and news agencies share their experiences."

Hurricane Matthew occurred during an incredible wave of social media pervasiveness and popularity. According to the Pew Research Center's Social Media Update 2016, published November 11, 2016, roughly 1 month after the hurricane, Facebook continues to be the most popular social networking platform in America. With nearly $79 \%$ of adult American Internet users maintaining a social presence on Facebook, this is greater than Twitter (24\%), Pinterest (31\%), Instagram (32\%), or LinkedIn (29\%; Greenwood, Perrin, \& Duggan, 2016). Facebook users typically visit the platform more regularly than users of other social media sites, with $76 \%$ of all active Facebook users reporting that they visit the site daily, $55 \%$ visiting several times a day, and $22 \%$ visiting about once per day (Greenwood et al., 2016).

Of note is the "modest but statistically significant increase" in 2016 from 2015, when only $70 \%$ of Facebook users indicated daily visits to the social networking site. On Instagram, 51\% of users access the site daily, and $35 \%$ visit several times a day. On Twitter, $42 \%$ of users are daily visitors, and $23 \%$ visit multiple times day (Greenwood et al., 2016).

\section{Rationale for Revisiting STREMII:}

\section{The Differences Between 2012 and Today}

When Pew Research Center (2017) began tracking social media data in 2005 , only $5 \%$ of American adults were using (at least) one social media platform, compared to today, when $69 \%$ of the American population is using some form of social media. As of February 2012, 
when Hurricane Sandy took place, only $14 \%-15 \%$ of online adults were using Twitter, and only $8 \%$ used the platform on a daily basis. This is noteworthy because the proportion of online American adults who used Twitter daily has quadrupled since 2010, when daily use was just 2\% (Smith \& Brenner, 2012). In August 2012, just prior to Hurricane Sandy, only 54\% of American adults were using Facebook; at the time of Hurricane Matthew in 2016, 68\% of the entire U.S. population was using Facebook (Pew Research Center, 2017). The increases in social media usage across the majority of the American population reveal the reliance on these popular communication channels during crisis events such as a natural disaster.

Shortly after the events of Hurricane Sandy, the U.S. Department of Homeland Security (2013), in conjunction with the Virtual Social Media Working Group, published a report available online titled Lessons Learned: Social Media and Hurricane Sandy, documenting how Sandy

marked a shift in the use of social media in disasters. More than ever before, government agencies turned to mobile and online technologies before, during, and after Sandy made landfall, to communicate with response partners and the public in order to share information, maintain awareness of community actions and needs, and more.

This report also "identified various gaps in technology, process, and policy; these gaps will require further discussion in order to enhance future response and collaboration efforts."

Additionally, Lin, Spence, Sellnow, and Lachlan (2016) revisited Seeger's (2006) best practices in crisis communication through social media. Seven practices emerged for emergency managers, crisis practitioners, and government agencies to consider when dialoguing with audiences via socially networked platforms:

1. Integrating social media into organizational decisions and policies

2. Monitoring, listening and responding to stakeholders' concerns, actively promoting dialog

3. Setting up official social media accounts to increase source credibility for information 
4. Scheduling timely, effective, relevant, and frequent updates of messages, to dispel rumors and decrease misinformation

5. Own and monitor the use of hashtags, in all phases of a crisis to ensure accuracy and usefulness

6. Cooperate with gatekeeper and "gatewatchers," keeping audiences in the information loop

7. Monitoring the social media landscape for rumors or misinformation (p. 604)

The authors concluded that social media present innovative opportunities for agencies and practitioners to reach, inform, and motivate audiences; these new platforms and the opportunities they invite require that crisis communicators constantly monitor the social media landscape (Lin et al., 2016). Young (2016) additionally offered revised best practices for integrating social media into crisis communication strategies, focusing on the implications for government agencies during natural disasters.

The Red Cross and the Federal Emergency Management Agency (FEMA) have recognized the value of social media and have changed the way they respond to disasters, turning to social listening, realizing that

the best information they can gather during an emergency or natural disaster does not come from their own government-built apps. It comes from existing social media channels.... Scott Shoup, chief data officer at FEMA [states], "Instead of trying to do everything ourselves, we need to find smarter ways to integrate the social media world more effectively into how we perform our business functions ... by monitoring social media outlets, collecting information in real time, and using it to act immediately." (Ogrysko, 2016)

The lack of predictability of hurricane crises emphasizes the importance of understanding more about the role of social media in crisis communication. For these reasons, we propose an extension of the original STREMII model to account for the ongoing needs for social listening and engagement with target audiences throughout the entire crisis and all of its phases, as well as during periods of noncrisis. We 
describe these extensions of the revised STREMII model through the discussion of examples from Hurricane Matthew and how they reveal the ongoing processes of social listening and responsive engagement that occurred at organizations and interpersonal communication levels during this particular hurricane event. With this is mind, this article explores the overarching question, How is STREMII exemplified within the social media landscape based on the crisis event of Hurricane Matthew?

\section{Theoretical Foundations}

To proactively assess the STREMII model in this changing social media climate and within the events of Hurricane Matthew and make a case for future application and investigation, we consider Coombs's (2007, 2014) situational crisis communication theory (SCCT) and revisit the STREMII model, briefly describing its original phases in the section to follow.

\section{Situational Crisis Communication Theory}

Coombs $(2007,2014)$ created SCCT as a theoretical framework for crisis and organizational communication research and practice. SCCT strategically maps effective crisis response to the degree of organizational responsibility and reputational threat brought about by the crisis, asserting that "crisis communication should be strategic; efforts should be designed to improve the situation for stakeholders and the firm in crisis" (Coombs, 2015, p. 141).

Coombs's research advised crisis managers to recognize the importance of evaluating the type of crisis, crisis history, and organizational reputation when trying to predict the level of crisis effects and reputational outcomes (positive or negative) for their organizations. Additionally, Coombs specified the ethical responsibilities for a crisis response, focusing on protecting stakeholders rather than reputation, through instructing information and adapting information. As crises create an informational void, affected individuals need to be told what to do to protect themselves physically, need information to cope with the event psychologically, and need to know that organizations are concerned for their welfare as victims. 
From a traditional perspective, SCCT emerges from a mass communication model focusing on media frames and a one-to-many communication flow. Today, the pervasive nature of social media culture challenges this directionality of communication and dictates dialogic interaction with stakeholders, as information flow is constant, is interactive, and involves individual users as message actors, agents, and creators (Utz, Schultz, \& Glocka, 2012).

Since 2007 , this theory has been tested, critiqued, and updated with information regarding the changing nature of crisis responses, including variables other than organizational reputation, namely, "negligence in providing base crisis responses (i.e., instructing and adjusting information)" (Kim \& Sung, 2014, p. 62). Despite advances in SCCT, natural disaster situations like hurricanes challenge this organization-centric tendency, as responsibility for the cause of the crisis cannot be attributed to any organizational wrongdoing. Instead, a dual or parallel responsibility evolves in which organizations are responsible for repair of their reputations as well as relationship and information management via legacy and social media.

As an example, FEMA recently launched an initiative to monitor social media during disasters in an attempt to save more lives and improve rescue efforts. Part of FEMA's responsibilities during disasters is to provide situational awareness for partners at the federal, state, local, tribal, and territorial levels as well as for international partners (Thomas, 2016). Now that we have considered SCCT, let us explore the life cycles of a crisis, particularly as they pertain to hurricane disasters.

\section{The Original STREMII Model of Social Media Crisis Communication}

Stewart and Wilson's (2015) STREMII model of social media crisis communication introduces a cyclical process for organizations to reference when engaging in crisis communication on social media. The six interconnected elements of STREMII include (a) surveillance and social listening, (b) targeting the appropriate audience, (c) responding to the crisis and conversation, (d) monitoring the landscape and evaluating outcomes, (e) interacting with consumers and publics, and (f) implementing necessary changes (Stewart \& Wilson, 2015). An illustration of this original model is presented in Figure 1. 


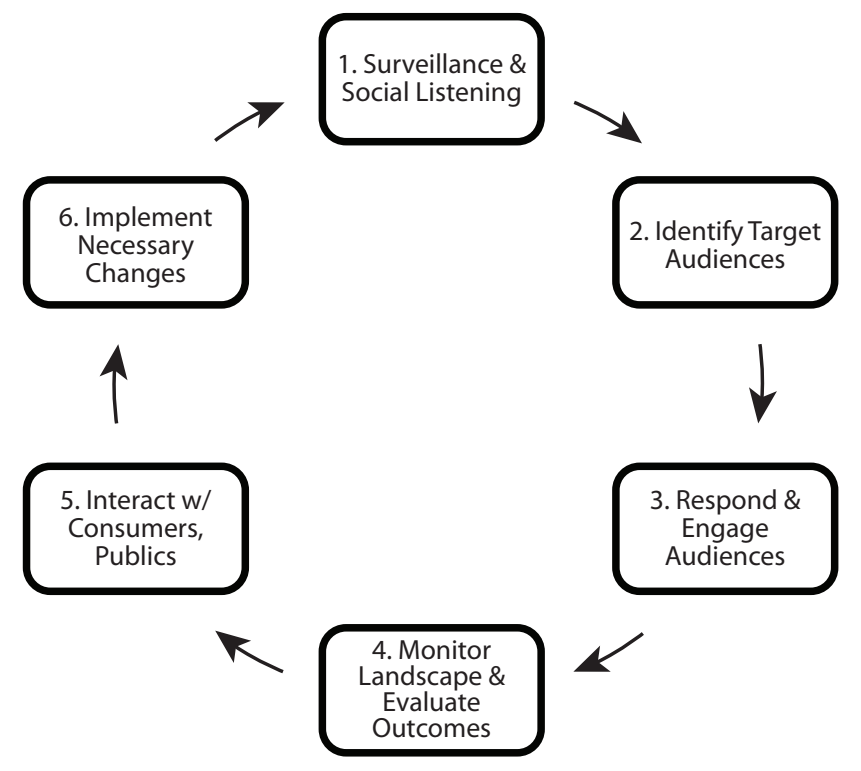

FIGURE 1 The STREMII (STREAM-ee) model of social media crisis communication (Stewart \& Wilson, 2015).

During the first phase of STREMII, social listening, crisis professionals attend to, process, and respond to the flow of information continuously from a wide range of social media sources before, during, and after crisis, which improves their ability to obtain information and respond accordingly on social media platforms (Lindsay, 2011). Stewart and Arnold (2017) defined social listening as "an active process of attending to, observing, interpreting, and responding to a variety of stimuli through mediated, electronic, and social channels" (p. 86); thus this critical first step of the STREMII model can be very empowering for an organization during a time of crisis, when decision makers truly need to gather information to provide an informed response to concerned or compromised stakeholders.

The second phase of STREMII is to target audiences. Social listening and targeting audiences go hand in hand in that social listening provides an opportunity to discover warning signs or false information on social media that can potentially trigger a crisis; identify influencers, advocates, and critics who can both potentially help or hinder crisis response; and determine which social media channels are most appropriate given the 
organizational or institutional culture and audience (Syme, 2014). The third phase of STREMII is response and engagement, which should be done in a timely and informed manner to stakeholders. When engaging with stakeholders during a crisis, it is important for organizations to acknowledge the crisis directly, disclose actions toward resolution and their anticipated timeline, be sympathetic and empathetic, be honest and straightforward, provide stakeholders with contact information and preferred communication channels, and remain timely with updates (Geller, 2014; Jaume, 2013). The phases of social listening and responsive engagement are revisited and recommended for ongoing procedures throughout the phases of a crisis event and even as the other steps of STREMII occur (Stewart \& Wilson, 2015).

In recognizing social listening as an ongoing activity when applying STREMII to a crisis, the fourth stage of STREMII is monitoring and evaluating outcomes, which is an extension of the social listening process. This phase typically occurs as the crisis is winding down or as the acute phase of the crisis has concluded, and organizational leaders implement resolution efforts, evaluate crisis communication measures, and continue ongoing interaction with consumers and publics during the fifth stage. Last, the sixth and final stage of the STREMII model is to implement necessary changes to the organization's social media crisis communication strategy based on what has been learned throughout the event (Stewart \& Wilson, 2015).

\section{Methodology}

Considering the question of how STREMII is exemplified within the social media landscape, this section describes the case study research method. Yin (2018) argued that a case study method is best for research inquiries based on how/why questions. Using this particular methodology "arises out of the desire to understand complex phenomena. Case studies allow you to focus in-depth on a 'case' ... [and study] organizational and managerial processes" (p. 6), within a contemporary (not historical) context. To be rigorous in application, researchers using the case study research method must identify the case, determine what data are to be collected as evidence, decide how to analyze the case, and report what was learned. 
Yin (2018) identified five rationales for selecting a single case: It should be critical for understanding a theory, provide an unusual outcome, represent a common occurrence, reveal a hidden aspect of a phenomenon, or provide longitudinal evidence. Out of the five rationales, we selected a common case "to capture the circumstances and conditions of an everyday situation [hurricane] ... because of the lessons it might provide about the social processes related to some theoretical interest" (Yin, 2018, p. 50). Because STREMII emerged from Hurricane Sandy, we chose Hurricane Matthew as a more contemporary case on which to focus.

For data, we collected organizational and interpersonal communication examples from online news articles and stories, timelines, social media posts, and personal experiences that revealed the complementary nature of social listening and engaging with stakeholders on social media. To analyze this information, we executed Yin's (2018) strategy, which involves following theoretical propositions and conducting an expansive and critical review of the literature. The next section highlights the role of social listening and responsive engagement at different phases of the crisis during Hurricane Matthew. These examples provide support for the revised model, which presents that social listening and engagement underpin the model. Last, we report what we have learned in the "Discussion" and "Conclusion" sections.

\section{Revisiting STREMII: Examples From Hurricane Matthew}

\section{Social Listening During Crisis}

As discussed earlier, the sheer number of social media channels available in 2016, when Hurricane Matthew occurred, revealed the expectation for social listening and more conversation among individuals and stakeholder groups. As such, there is a constant opportunity to tune in to relevant conversations, carefully consider and assess the messages, develop appropriate responses, and engage accordingly. This process, essentially described as social listening, is defined as "an active process of attending to, observing, interpreting, and responding to a variety of stimuli through mediated, electronic, and social channels" (Stewart \& Arnold, 2017, p. 86). The increase in connectivity from social media 
influences how we attend and respond to mediated messages. Social listening has implications within organizational communication as well as in interpersonal relationships.

Cofounder and president of Shoutlet Aaron Everson described social listening as monitoring activity on social networks. This is achieved by tracking keywords, performing customer service, or analyzing hashtag or brand handles; the information potentially gathered through social listening inspires ideas based directly on the behavior of the consumer base (Wagner, 2014). According to Crawford (2009), listening to social media interactions online potentially alters the relationship between organizations and consumers because it enables a dynamic communication environment full of e-word-of-mouth and influencer opportunities. Research has suggested that conversations and social interactions are happening constantly, so during a crisis event, the ongoing challenge is to channel them, capture them, and integrate them into actionable insights (De Clerck, 2016). Social listening becomes urgent because of its immediacy of rich information and its global scope and because it contributes well to the development of actionable insights (Genpact, 2012). These insights influence efforts for effective and responsive engagement.

There were several examples of social listening during Hurricane Matthew at both organizational and interpersonal levels. During Hurricane Matthew, citizens, agencies, and organizations relied on social listening through global and hyperlocal coverage. Many people posted videos, photos, and updates from the storm, capturing and documenting their experiences from their individual locations. A Port St. Lucie resident, Isaac Cubillos, posted significant video, picture, and text context about the storm and used social media to check in on his friends, neighbors, and loved ones, commenting,

Social media allows for the connection that brings us closer during severe conditions like this hurricane. It let my friends and family know how I was and the conditions of the environment that they would not get from network broadcast. (Pacenti, 2016)

Lives were even spared due to the impact of social media and the real-time communication value it affords. Chris Williams, a veteran, 
and his dog Lana were stranded inside their home and were at risk of being flooded out as waters rose. A social media account shared a drone image of flooded homes. Chris's brother saw the image and recognized one home as belonging to his brother. Not surprisingly, when his brother reached out to rescuers for help, they were overwhelmed with calls, so instead the brother used social media to contact the citizen who posted the image. Curiously enough, the man with the drone also used the drone device to capture the attention of nearby rescuers, who were able to come in and save Chris and his dog. The drone provided the rescue team with Chris and Lana's specific location (Joseph, 2016). This example of Chris and Lana reveals how social listening during a crisis contributes to increased online engagement followed by actionable response, and these instances demonstrate the interpersonal side of social listening during a crisis event such as Hurricane Matthew.

From an organizational perspective, police, fire, government, and emergency officials all seemed to gravitate to Twitter as their platform of choice to distribute information during Hurricane Matthew (Pacenti, 2016). The National Oceanic and Atmospheric Administration (2016) published a list of social media accounts to follow before, during, and after the storm-including links to get local storm information and forecasts; links to national, state, and local emergency management offices like FEMA; and links to county resources in Florida, Georgia, and the Carolinas. Encouraging the public to access information using social media channels is a relatively new historical milestone in natural disaster crisis response.

\section{Continuous Responsive Engagement}

A hurricane in the digital technology era where a drone and a picture on social media had a role in saving the lives of a man and his dog during vicious hurricane flooding demonstrates the emerging importance of social media during natural disaster events. The picture was posted to Instagram and Twitter along with the hashtag \#HopeMills, and by social listening to the conversation affiliated with this hashtag, Craig Williams, who lives in Texas, was able to intervene on behalf of his brother Chris. Scrolling through Twitter looking for posts tagged \#HopeMills, he contacted Chris via Facebook messenger to cheer him up when it 
turned out his was one of the homes in trouble. When Craig's repeated 911 calls could not get through, Craig wrote on a GoFundMe page for his brother and decided to reach out to the owner of the original post directly. The man deployed the drone back out to Chris and was able to flag down a FEMA boat to intervene (Joseph, 2016).

A new social media feature that was revolutionary during the Hurricane Matthew crisis was Facebook Live, which launched only 9 months prior to Hurricane Matthew, in January 2016. With Facebook's recently launched Facebook Live feature making waves and the SnapChat platform growing at an incredible rate, as the first major hurricane of the Periscope era, Hurricane Matthew demonstrates technological determinism during crisis. Periscope is a mobile video-streaming platform acquired by Twitter. Mobile live streaming allows social media users to initiate a public or private video broadcast, and viewers can send comments as they watch. In the case of Hurricane Matthew, several Florida news networks, such as WPEC in West Palm Beach and WSVN in Miami, used Periscope and Facebook Live to broadcast online news coverage. During Hurricane Matthew, a single live stream on WPEC gathered an audience of more than 700,00o viewers (King, 2016).

Facebook Live and streaming video are not only critical to the engagement among new organizations during a story but are also incredibly popular at an interpersonal level. Citizens used Facebook Live to bring the storm to life, especially to share with families, friends, and loved ones across the county who were not able to see the events in person. Citizens praised the organic nature of the live stream content during the storm and expressed appreciation for the ability to be part of a live conversation that allowed for comments and conversation. One Periscope video from storm chaser Jeff Piotrowski is said to have gained an audience of more than 92,00o viewers. During Hurricane Matthew, Periscope set up a channel dedicated exclusively for live streams from the storm (King, 2016).

Pacenti (2016) indicated that Hurricane Matthew resulted in a social media storm as citizens took to Facebook, Twitter, Instagram, and SnapChat to chronicle the storm event. Instagram and Facebook featured countless hurricane photos. The \#hurricanematthew2016 hashtag showed photos ranging from \# evacuationparty to hunkering down and 
reinforcing doors and windows and, of course, the roaring ocean. Many of the images also captured the true damage and destruction of the storm. SnapChat compiled video that revealed a montage of hurricane experiences and damages. Facebook opened its Safety Check feature during the storm so that people could alert friends and family of their safety. All of this social media frenzy during the hurricane influenced organizational response in that companies such as AT\&T waived fees for data usage during the period of the storm in areas affected (King, 2016; Pacenti, 2016).

The Facebook Safety Check is a feature that is critical to interpersonal and organizational response during a storm crisis. Facebook activates the Safety Check feature to enable users to alert their loved ones, friends, and family that they are safe during a dangerous event or natural disaster. Examples where Safety Check is put in use include the 2015 Paris terrorist attacks and the 2016 Orlando nightclub shooting. Facebook issued a statement that "our hearts go out to the people affected by this tragic event. We hope the people in the area find the tool a helpful way to let their friends and family know they are okay" (Chang, 2016). On a global scale, Facebook's responsiveness regarding activating the tool has been criticized. For instance, during Hurricane Matthew, the Safety Check was turned on when the storm made its way toward the United States rather than while it was in Haiti. Given that the tool is fewer than 3 years old, there is speculation as to its saliency (Chang, 2016).

The intersection between the digital and live events of Hurricane Matthew provides an ample case for consideration of these critical stages during a hurricane crisis event. Features such as live streaming and Safety Check are noteworthy developments that directly impact how crisis communication on social media during natural disaster events occurs. These new features warrant a different type of approach for organizational response during a crisis and simultaneously recognize the interpersonal attributes and individual power of social media. The case of Hurricane Matthew reminds us that social media during a crisis can enable our ability to communicate and share information with members of these networks. Thus understanding more about social media crisis communication will continue to be vital, and maintaining 
knowledge of how changing social media platform features affect the social media landscape is necessary. With these examples in mind, we revisit the overarching question and discuss next steps for academic and practical research of STREMII.

\section{Discussion}

This article set out to revisit the STREMII model, originally derived through an analysis of Hurricane Sandy in 2012. This article considered how certain elements of the model evolve related to changes in the social media landscape, including different features and platforms. Today, we recognize that social listening and responsive engagement are continuously interwoven throughout the other cyclical phases of STREMII, which is discussed more within this final section, along with limitations, next steps, and future research opportunities.

\section{Evolving STREMII}

The necessity for ongoing social listening and responsive engagement throughout the phases of the original STREMII model is supported in the interpersonal and organizational examples of social media crisis communication during Hurricane Matthew. With this in mind, a slightly revised visual representation of the STREMII model is designed. Figure 2 displays the latest STREMII image for recognition as a contemporary social media crisis communication model.

\section{Revisiting Best Practices}

When considering Lin et al's (2016) extension of Seeger's (2006) best practices in social media crisis communication, social listening and responsive engagement are encompassed in each of the presented practices. For examples, integrating social media into organizational decisions and policies would likely involve an aspect of social listening and responsive engagement within a developed social media strategy. Monitoring, listening to, and responding to stakeholders' concerns exemplify social listening activities, and actively promoting dialog would include responsive engagement. Responsive engagement would also be demonstrated when setting up official social media accounts 


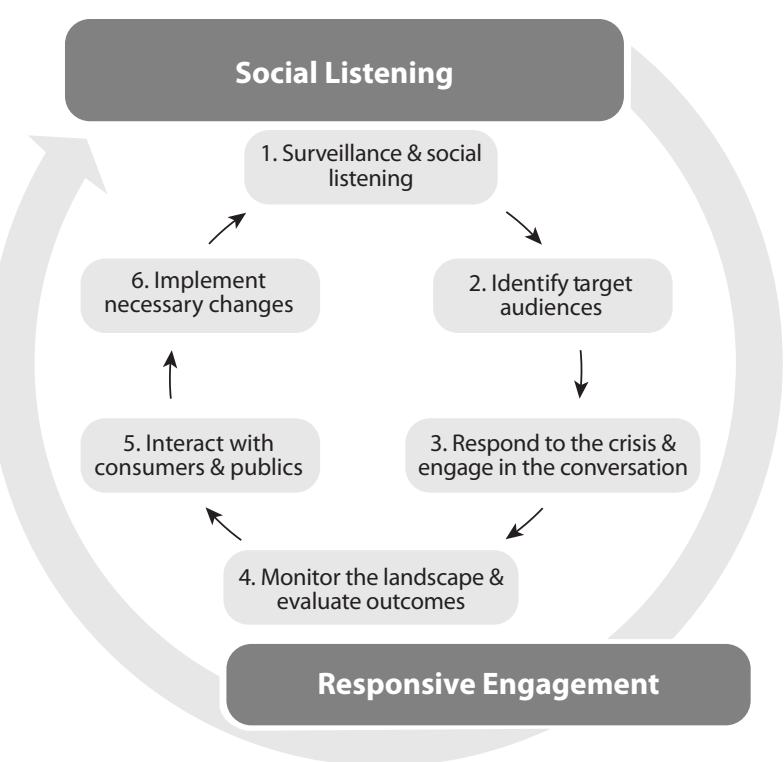

FIGURE 2 Revised STREMII model.

to increase source credibility for information, as well as scheduling timely, effective, relevant, and frequent updates of messages, to dispel rumors and decrease misinformation. Social listening is represented in the owning and monitoring of the use of hashtags in all phases of a crisis to ensure accuracy and usefulness. Cooperating with gatekeeper and "gatewatchers" and keeping audiences in the information loop (Lin et al., 2016) imply responsive engagement.

Last, several interpersonal and organizational examples are cited and discussed throughout this article. Also, recognizing the difference in the social media climate between Hurricane Sandy and Hurricane Matthew, as mentioned by the Red Cross and FEMA, shows the value of social media, and organizations have realized that they can use social media as information tools to effectively respond to disasters (Ogrysko, 2016). FEMA recently launched an initiative to monitor social media during disasters in an attempt to save more lives and improve rescue efforts (Thomas, 2016). These organizations are now turning to social listening as they realize that the information that can be gathered from online conversations is rich and valuable. Social listening affords real- 
time surveillance by monitoring social media outlets, attending to and processing that information in real time, and using it to provide immediate and effective responses (Ogrysko, 2016).

\section{Limitations}

Von Mending and Forino (2016) lamented that "disasters are not a natural phenomenon. Humans play a central role. As a result, a natural hazard such as Hurricane Matthew impacts each country in its path differently." One of the limitations of this study is that we primarily focused on the impact of Hurricane Matthew within the United States. Future research on social media crisis communication should take into consideration an additional situational variable: international crisis communication response strategies. Included in this variable would be differences in cultural approaches to disasters, differences in the uses and functions of social media, and difficulties with language barriers when responding to multilingual audiences. As an example, in the event of the Pulse nightclub shooting in Orlando, the Hispanic community had different informational needs than the LGBTQ community.

Second, the original STREMII model grew out of and has been applied within the context of hurricanes. This model and its application presently do not extend to other types of organizational crises and events as they are both created and managed in social media (STREMII is limited to managing crises only). To date, research on the STREMII model has been exploratory. Thus it makes sense that the next steps would include more practical development for use of the model in applied research as well as empirical testing.

\section{Next Steps}

There is a gap in the existing STREMII literature when it comes to the procedure of each stage of the model. We recognize that the audience interested in STREMII would benefit from a practical explanation about how to use it, namely, what to do at each stage of the model and how to integrate the model into existing crisis communication and social media strategies. While we have explained the purpose of each stage of the model clearly and showcased these purposes through various hurricane crisis examples across two storms, we recognize the clear 
and obvious opportunity to enhance the understanding of STREMII by providing a practical process for implementation. Our next step for this line of inquiry is to extend beyond the theoretical knowledge about the model and to present the how-to process of STREMII.

\section{Opportunities for Future Research}

There are several options for next steps to explore STREMII. Using SCCT and/or the best practices for crisis communication on social media, STREMII is able to support matching the social media response of the crisis to the nature and impact of the crisis itself. As discussed, further pragmatic application would surely benefit the analysis and evaluation of the effectiveness of STREMII through the use of case study research methods. STREMII is posited and developed for natural disasters, but further analysis may reveal applicability to other types of organizational crises as well. If so, then it will be beneficial to examine the nuances of STREMII applications across several different types of crisis events and determine if any differences in the process occur or are necessary based on the nature of the crisis event.

In addition, STREMII is a model that is beneficial for classroom pedagogy within crisis communication courses (Stewart \& Young, 2016). The revised model has yet to be tested or evaluated within the classroom; however, feedback from previous pedagogical applications of the original model was considered in its redesign. This presents a similar opportunity for the current model to be discussed and analyzed within the classroom setting using an identical pedagogical procedure so that longitudinal data regarding the model as it progresses can be gathered and aggregated over time. Last, as more social media research develops, the opportunity exists for empirical testing of the STREMII model. Once the procedure for the model is introduced and the model is used for practical implementation, appropriate measures can be determined for how to best evaluate the model.

\section{Conclusion}

As social media continuously evolve, STREMII will have to be periodically evaluated and redeveloped. STREMII has the potential to become 
a dynamic social media crisis communication model that will advance over time and progress in tandem with the social media landscape. The utility of STREMII for social media crisis communication for natural disasters, specifically hurricanes, invites further practical scholarship. Understanding the model and its extensions more clearly considers how this process can be integrated into an organization's existing social media strategy to be prepared in the event of a hurricane or other weather-related natural disaster. This current research also reflects on how STREMII may apply to other types of crisis events. For now, STREMII provides a versatile framework to guide crisis communication on social media during hurricane events through a carefully designed process based on examples from actual storm events, with a recent emphasis on the areas of social listening and engagement.

Margaret C. Stewart, $\mathrm{PhD}$, is an assistant professor of communication studies at the University of North Florida in Jacksonville, where she teaches Public Speaking for Professionals, Principles of Communication Studies, and Strategic Social Media. She is a certified social media strategist and trainer for the National Institute of Social Media and a consultant for Socially Inspired, LLC.

Cory Young, $\mathrm{PhD}$, is an associate professor in the Department of Strategic Communication at Ithaca College in upstate New York. She is primarily responsible for teaching corporate and organizational communications, specializing in crisis communication and social media.

\section{ORCID}

Margaret C. Stewart (i) https://orcid.org/oooo-0oo2-9285-8623

\section{References}

Chang, L. (2016, October 9). Let friends know you're safe from Hurricane Matthew with Facebook Safety Check. Retrieved from http://www.digitaltrends .com/social-media/facebook-safety-check-hurricane-matthew/ 
Coombs, W. T. (2007). Protecting organization reputations during a crisis: The development and application of situational crisis communication theory. Corporate Reputation Review, 10, 163-176. https://doi.org/10.1057 /palgrave.crr.1550049

Coombs, W. T. (2014). Ongoing crisis communication: Planning, managing, and responding (4th ed.). Thousand Oaks, CA: Sage.

Coombs, W. T. (2015, March-April). The value of communication during a crisis: Insights from strategic communication research. Business Horizons, 58, 141-148. https://doi.org/10.1016/j.bushor.2014.10.003

Crawford, K. (2009). Following you: Disciplines of listening in social media. Continuum (Perth), 23, 525-535. https://doi.org/10.1080/10304310903003270

De Clerck, J. (2016). Social CRM: Social and communities in CRM and marketing. Retrieved from http://www.i-scoop.eu/social-crm-social-communities-crm -marketing/

Drye, W. (2016, October 13). Hurricane Matthew: The timeline. National Geographic. Retrieved from http://voices.nationalgeographic.com/2016/10/13 /hurricane-matthew-the-timeline/

Geller, L. (2014, September 16). Outstanding customer service in social media. Forbes. Retrieved from https://www.forbes.com/sites/loisgeller/2014/og/16 /outstanding-customer-service-in-social-media/\#630564753425

Genpact. (2012). Social listening: Turning conversation into actionable insights. Retrieved from http://www.genpact.com/insight/social-listening-turning -conversation-into-actionable-insights

Greenwood, S., Perrin, A., \& Duggan, M. (2016, November 11). Social media update 2016: Facebook usage and engagement is on the rise, while adoption of other platforms holds steady. Retrieved from http://www.pewinternet .org/2016/11/11/social-media-update-2016/

Jaume, J. (2013, February 13). Using social media monitoring for crisis management. Brandwatch. Retrieved from https://www.brandwatch.com/blog /using-social-media-monitoring-for-crisis-management/

Joseph, R. (2016). Hurricane Matthew: Drone picture leads to rescue of man trapped by storm. Retrieved from http://globalnews.ca/news/2995403/hur ricane-matthew-social-media-picture-leads-to-rescue-of-man-trapped -by-storm/

Kim, S., \& Sung, K. H. (2014). Revisiting the effectiveness of base crisis response strategies in comparison of reputation crisis management responses. 
Journal of Public Relations Research, 26, 62-78. https://doi.org/10.1080 /1062726X.2013.795867

King, H. (2016, October 7). People are live-streaming Hurricane Matthew. Retrieved from http://money.cnn.com/2016/10/o7/technology/hurricane -matthew-live-stream-periscope/index.html

Lin, X., Spence, P. R., Sellnow, T. L., \& Lachlan, K. A. (2016). Crisis communication, learning and responding: Best practices in social media. Computers in Human Behavior, 65, 601-605. https://doi.org/10.1016/j.chb.2016.05.080

Lindsay, B. R. (2011, September 6). Social media and disasters: Current uses, future options, and policy considerations. Retrieved from http://www .infopuntveiligheid.nl/Infopuntdocumenten/R41987.pdf

National Oceanic and Atmospheric Administration. (2016). Stay connected. Retrieved from http://www.noaa.gov/stay-connected

Ogrysko, N. (2016, March 24). FEMA, HHS turn to "social listening" for better disaster response. Federal News Radio. Retrieved from http://federalnews radio.com/digital-government/2016/03/fema-hhs-turn-social-listening -better-disaster-response/

Pacenti, J. (2016, October 7). Social media turned into a real storm during Hurricane Matthew. Palm Beach Post. Retrieved from http://www.palm beachpost.com/weather/hurricanes/social-media-turned-into-real-storm -during-hurricanematthew/IEPUkVfB1yCxwD99bldS9O/

Pew Research Center. (2017, January 12). Social media fact sheet. Retrieved from http://www.pewinternet.org/fact-sheet/social-media/

Seeger, M. W. (2006). Best practices in crisis communication: An expert panel process. Journal of Applied Communication Research, 34, 232-244. https:// doi.org/10.1080/00909880600769944

Smith, A., \& Brenner, J. (2012, May 31). Twitter use 2012. Retrieved from http:// www.pewinternet.org/2012/05/31/twitter-use-2012/

Stewart, M. C., \& Arnold, C. L. (2017). Defining social listening: Recognizing an emerging dimension of listening. International Journal of Listening, 32(2), 85-10o. https://doi.org/10.1080/10904018.2017.1330656

Stewart, M. C., \& Wilson, B. G. (2015). The dynamic role of social media during Hurricane\#Sandy: An introduction of the STREMII model to weather the storm of the crisis lifecycle. Computers in Human Behavior, 54, 1-8. https://doi.org/10.1016/j.chb.2015.07.009

Stewart, M. C., \& Young, C. (2016, March). Bridging the gap in social media 
crisis communication: Pedagogical applications of the STREMII model. Presentation delivered at the International Crisis and Risk Communication Conference, Orlando, FL.

Syme, C. (2014, April 21). Monitoring social media to prevent a crisis. SocialMediaToday. Retrieved from http://www.socialmediatoday.com/content /monitoring-social-media-prevent-crisis

Thomas, C. (2016, August 16). FEMA to monitor social media during disasters. Retrieved from http://odf.nvoad.org/fema-to-monitor-social-media -during-disasters/

U.S. Department of Homeland Security. (2013, June). Lessons learned: Social media and Hurricane Sandy. Retrieved from https://www.dhs.gov/publica tion/lessons-learned-social-media-hurricane-sandy

Utz, S., Schultz, F., \& Glocka, S. (2012). Crisis communication online: How medium, crisis type, and emotions affected public reactions in the Fukushima Daiichi nuclear disaster. Public Relations Review, 39, 40-46. https:// doi.org/10.1016/j.pubrev.2012.09.010

von Mending, J., \& Forino, G. (2016, October 11). Hurricane Matthew is just the latest unnatural disaster to strike Haiti. Retrieved from https://thecon versation.com/hurricane-matthew-is-just-the-latest-unnatural-disaster -to-strike-haiti-66766

Wagner, V. (2014). Hear, hear: The rise of social listening. CRM Buyer. Retrieved from http://www.crmbuyer.com/story/81409.html

WTHR Indianapolis. (2016, October 7). Social media following and reacting to Hurricane Matthew. Retrieved from https://www.wthr.com/article /social-media-following-and-reacting-to-hurricane-matthew

Yin, R. K. (2018). Case study research and applications: Design and methods (6th ed.). Los Angeles, CA: Sage.

Young, C. (2016). Crisis and risk communications: Best practices revisited in an age of social media. In J. L Drake, Y. Y Kontar, J. C. Eichelberger, T. S. Rupp, \& K. M. Taylor (Eds.), Communicating climate change and natural hazard risk and cultivating resilience: Case studies for a multi-disciplinary approach (pp. 27-36). Bern, Switzerland: Springer. 